\title{
ESTUDO DO COMPORTAMENTO DE BLENDAS DE POLIAMIDA 6/RESÍDUO DE BORRACHA DA INDÚSTRIA DE CALÇADOS
}

\section{STUDY OF THE BEHAVIOR OF BLENDS OF POLYAMIDE 6/WASTE RUBBER IN THE FOOTWEAR INDUSTRY}

\author{
Carlos Bruno Barreto Luna ${ }^{1}$ \\ Divânia Ferreira da Silva² \\ Edcleide Maria Araújo ${ }^{3}$
}

Resumo: O reaproveitamento de borrachas tem sido bastante explorado, por meio de misturas com polímeros virgens, para gerar compostos utilizados em diversas aplicações. $O$ objetivo deste trabalho foi produzir blendas poliméricas a partir de uma matriz de poliamida $6 \mathrm{com}$ resíduos de borracha reciclada (SBR-R). Foram realizados estudos sobre reologia, temperatura de deflexão térmica (HDT), análise térmica dinâmico-mecânica (DMTA) e espectroscopia na região do infravermelho com transformada de Fourier (FTIR). As blendas de poliamida 6/resíduo de borracha reciclada foram preparadas em uma extrusora de rosca dupla corrotacional e os grânulos extrusados foram moldados por injeção. Os resultados obtidos com o estudo reológico mostraram que quanto maior a percentagem de SBR-R adicionado, maiores os valores de torque. As temperaturas de deflexão térmica das blendas reduziram pouco, quando comparadas à da poliamida 6. No ensaio de DMTA, as blendas binárias e ternárias tiveram deslocamento dos picos para, aproximadamente, $-10^{\circ} \mathrm{C}$ e o deslocamento da relaxação $\alpha$ da $P A 6$, para valores maiores. Os resultados do FTIR evidenciaram que as bandas características da PA6 não foram modificadas pela presença do SBR-R e nem pelo aumento da percentagem nas blendas binárias e pela presença de PE-g-MA nas blendas ternárias, mostrando que os seus grupamentos químicos não foram afetados.

Palavras-chave: reaproveitamento; blendas poliméricas; PA6; SBRR; compatibilizante.

Abstract: The reuse of rubber has been extensively explored with mixtures with virgin polymers to generate compounds used in various applications. The aim of this work was to produce polymer blends from an array of polyamide 6 with recycled rubber waste (SBR-R). Rheology testing, heat deflection temperature (HDT), dynamic mechanical thermal analysis (DMTA), and Fourier transform infrared spectroscopy (FTIR) were performed. The blends of polyamide 6/recycled rubber waste were prepared in a twin-screw corrotational extruder and the extruded granules were molded by injection. The results obtained with rheological study showed that the greater the percentage of SBR-R added, the higher the torque values. The heat deflection temperatures of the blends decreased slightly when compared to polyamide 6. In the DMTA test, binary and ternary blends showed a shift of the peaks of approximately $-10^{\circ} \mathrm{C}$ and the displacement of the $\alpha$ relaxation of $P A 6$ toward larger values. The results of the FTIR showed that the characteristic peaks of PA6 were not modified by the presence of SBR-R nor by increasing the percentage in the binary blend and the presence of PE-g-MA in ternary blends, where their chemical groups were not affected.

Keywords: reuse; polymer blends; PA6; SBRR; compatibilizer.

\footnotetext{
${ }^{1}$ Graduando em Engenharia de Materiais - Universidade Federal de Campina Grande - UFCG, Brasil e Bolsista PIBIC (Programa Institucional de Bolsas de Iniciação Científica) / CNPq (Conselho Nacional de Desenvolvimento Científico e Tecnológico) da UFCG. E-mail: brunobarretodemaufcg@hotmail.com.

${ }^{2}$ Mestra em Ciência e Engenharia de Materiais - UFCG e Doutoranda em Ciência e Engenharia de Materiais - UFCG. Email: divaniaf@yahoo.com.br.

${ }^{3}$ Doutora em Ciência e Engenharia de Materiais - UFCG e Professora Efetiva da Unidade Acadêmica de Engenharia de Materiais - UFCG. E-mail: edcleide@dema.ufcg.edu.br.
} 


\section{INTRODUÇÃO}

O elevado volume de resíduos sólidos urbanos e industriais é uma das grandes preocupações deste século. Resíduos são partes significativas dos ciclos da natureza e da economia, onde podem ocorrer perdas de matéria e energia. A industrialização elevou a quantidade de resíduos consideravelmente, os quais, muitas vezes, têm destino final inadequado ou não aceitável, do ponto de vista econômico e ambiental (SERRANO, 2009).

Os polímeros, sejam eles plásticos ou borrachas, figuram na mídia como uma espécie de vilões ambientais. Atualmente, grandes quantidades de borrachas são consumidas mundialmente, mas, quase que integralmente, a borracha pós-consumo requer um longo período para sua degradação, não somente devido à estrutura reticulada, mas também pela presença de estabilizadores e outros aditivos presentes em sua formulação (SILVA, 2011).

É de grande importância a reciclagem de materiais poliméricos, portanto, programas governamentais visando a promover a conscientização da população para os problemas associados ao descarte do lixo urbano e industrial, fizeram com que, hoje, as reciclagens de metais, vidros, termoplásticos e borrachas sejam realizadas em diversas partes do mundo (ARAÚJO; CARVALHO; MARCUS, 1997). Os resíduos de borracha, oriundos das indústrias de calçados e de pneus, são fonte de poluição ambiental e desperdício de matéria-prima com boas propriedades e alto valor agregado. Sabe-se que esses materiais apresentam resistência relativamente alta a agentes biológicos e às intempéries, causando, assim, sérios problemas à comunidade em geral quando descartados. Tanto os aspectos econômicos quanto a poluição ambiental são justificativas para que também se envidem esforços no sentido de promover a reciclagem desses materiais poliméricos (SILVA; ARAÚJO; MELO, 2012).

Uma das maneiras de se reaproveitar os resíduos de borrachas é por meio de misturas com termoplásticos. Nesses casos, os resíduos infusíveis dispersam-se na matriz termoplástica durante o processamento, atuando como cargas flexíveis. As misturas poliméricas ou blendas constituem uma alternativa para a obtenção de materiais poliméricos com propriedades que, em geral, não são encontradas em um único material, além disso, têm sido uma das principais técnicas de reaproveitar os resíduos de borrachas (ARAÚJO, 2001).

As poliamidas pertencem a uma classe de polímeros atraente para aplicações em engenharia, devido à combinação de propriedades, como: baixa viscosidade no estado fundido, boa resistência ao impacto sem entalhe e excelente resistência química. Por outro lado, as poliamidas são altamente higroscópicas e sensíveis ao entalhe, isto é, são dúcteis, quando não entalhados, mas fraturam, de maneira frágil, quando entalhados, devido à sua baixa resistência à propagação da trinca. As poliamidas tendem a ser frágeis em temperaturas subambientes e carregamento sob condições severas. Essas deficiências podem ser melhoradas pela mistura desses polímeros com outros polímeros (OLIVEIRA; LAROCCA; PESSAN, 2011). Uma maneira de se contornar essas limitações é preparar blendas poliméricas, em que um dos componentes é um elastômero (BARRA et al., 2003). 
O copolímero de estireno butadieno (SBR) é um elastômero que possui propriedades, como, por exemplo, razoável resistência ao envelhecimento, boa resistência à abrasão, boa resistência à água do mar, boas propriedades a baixas temperaturas, são largamente empregados na indústria de artefatos em geral, como em peças mecânicas, forros de carpetes e tapetes, em solas de calçados, adesivos e modificadores de asfalto. Cerca de $50 \%$ dos pneus são feitos a partir de vários tipos de SBR. A razão de estireno/butadieno influencia as propriedades do polímero, com elevado teor de estireno, as borrachas são mais duras e menos elásticas (SILVA et al., 2013).

A maioria das blendas PA6/elastômeros é imiscível, ou seja, existe segregação de fases. Uma vez que existe uma grande diferença de polaridade entre a poliamida e a maioria das borrachas, boa dispersão da fase elastomérica pode ser obtida apenas depois da modificação da interface (CARONE JÚNIOR, 1999). Em blendas imiscíveis, têm-se como consequência a incompatibilidade química entre os componentes, possuindo elevada tensão interfacial, baixa adesão entre as fases, e apresentando um sistema multifásico. Para contornar esse problema, é necessária a adição de um compatibilizante, copolímero em bloco ou enxertado, que pode reagir quimicamente com uma fase e interagir fisicamente com a outra, formando um copolímero in situ na interface (AGRAWAL; ARAUJO; MELO, 2008).

O presente trabalho teve como objetivo desenvolver blendas de PA6, com resíduos de borrachas provenientes da indústria de calçados, e caracterizar as blendas sem e com o compatibilizante polietileno enxertado com anidrido maleico (PE-g-MA), por meio das técnicas de reometria de torque, temperatura de deflexão térmica (HDT), análise térmica dinâmicomecânica (DMTA) e espectroscopia no infravermelho com transformada de Fourier (FTIR).

\section{METODOLOGIA EXPERIMENTAL}

\subsection{Materiais}

Matriz Polimérica

Foi utilizada uma poliamida 6 (PA6), Technil C216 de média massa molar (10.500 g/mol), índice de viscosidade IV=134ml/g, na forma de grânulos, fornecida pela Rhodia/SP.

\section{Fase Dispersa}

Foi utilizado o resíduo de borracha (SBR-R), proveniente da indústria de calçados São Paulo Alpargatas S.A (Sandálias Havaianas), da região de Campina Grande/PB. Este composto é constituído de uma mistura complexa de copolímero de estireno-butadieno (SBR), cargas, aditivos de processamento, agentes de cura e estabilizantes. 
Compatibilizante

Foi utilizado o polietileno (PE-g-MA), Polybond 3009, com índice de fluidez 5g/10min e enxertado com $1 \%$ em peso de anidrido maleico, fornecido pela Crompton/SP.

\subsection{Método}

Preparação das blendas

Antes de cada etapa de processamento, a PA6 e o compatibilizante foram secos em estufa, a vácuo, a $80^{\circ} \mathrm{C}$, por 48 horas. As blendas binárias PA6/SBR-R foram preparadas nas proporções em peso 90/10 e 80/20\% e as misturas ternárias PA6/SBR-R/PE-g-MA, nas proporções em peso $87,5 / 7,5 / 5$ e 77,5/17,5/5\%. A fase dispersa das blendas foi passada numa peneira ABNT № $35(425 \mu \mathrm{m})$. As blendas foram processadas em uma extrusora dupla rosca corrotacional da Coperion ZSK $18 \mathrm{~mm}$, com temperatura de $240^{\circ} \mathrm{C}$, em todas as zonas, velocidade de $300 \mathrm{rpm}$ e taxa de alimentação de $4 \mathrm{~kg} / \mathrm{h}$. A poliamida 6 pura foi extrudada nas mesmas condições das blendas. A PA6, as blendas binárias e ternárias extrudadas foram moldadas por injeção, na forma de corpos de prova, para ensaios de HDT (ASTM D648) e DMTA (corpos de prova tipo Izod, segundo a norma ASTM D256).

\subsection{Técnicas de caracterizações}

Reometria de torque

Os ensaios de reometria de torque foram realizados em um misturador interno RHEOMIX 600, acoplado a um Reômetro de Torque System 90, da Haake Büchler, operando com rotores do tipo roller, velocidade de rotação de $60 \mathrm{rpm}$, sob temperatura de $240^{\circ} \mathrm{C}$, por 20 minutos, em atmosfera de ar. A massa total, dentro da câmara de mistura, foi mantida constante em $55 \mathrm{~g}$ para todas as composições. Foram obtidas curvas reológicas dos seguintes materiais PA6, SBR-R, PE-g-MA, e das blendas de PA6/SBR-R sem compatibilizante, nas composições de 90/10, 80/20, 70/30, 60/40 (\% em peso) e 87,5/7,5/5; 77,5/17,5/5; 67,5/27,5/5 e 57,5/37,5/5 (\% em peso) para as blendas de PA6/SBR-R com compatibilizante.

Temperatura de deflexão térmica (HDT)

A temperatura de deflexão térmica (HDT) foi obtida, conforme a norma ASTM D648, em um equipamento Ceast, modelo HDT 6 VICAT, com uma carga de $455 \mathrm{kPa}$, taxa de aquecimento de $120^{\circ} \mathrm{C} / \mathrm{h}$ (método $\mathrm{A}$ ). A temperatura foi determinada após a amostra ter defletido $0,25 \mathrm{~mm}$. Uma série de 6 amostras foi ensaiada e a temperatura de deflexão térmica medida. 
Análise térmica dinâmico-mecânica (DMTA)

A análise térmica dinâmico-mecânica (DMTA) foi realizada em um equipamento de DMTA, da marca TA Instruments Explorer, modelo Q 800. O modo de solicitação dinâmicomecânico utilizado foi o de flexão em um ponto. Foram utilizados corpos de prova tipo Izod do mesmo tipo do ensaio de impacto (norma ASTM D256). A taxa de aquecimento utilizada foi de $10^{\circ} \mathrm{C} /$ min e frequência de $1 \mathrm{~Hz}$, na faixa de temperatura de -100 a $150^{\circ} \mathrm{C}$. Os resultados foram analisados em uma média de 6 corpos de prova.

Espectroscopia na região do infravermelho com transformada de Fourier (FTIR)

A espectroscopia na região do infravermelho foi realizada em um espectrômetro PERKIN-ELMER SPECTRUM 400, com varredura de 4000 a $650 \mathrm{~cm}^{-1}$. As análises de FTIR foram realizadas em filmes produzidos das blendas.

\section{RESULTADOS}

\subsection{Reometria de torque}

Foram utilizadas as composições para as blendas binárias de 90/10, 80/20, 70/30 e $60 / 40$ (\% em peso) e para as blendas ternárias 87,5/7,5/5, 77,5/17,5/5, 67,5/27,5/5 e $57,5 / 37,5 / 5$ (\% em peso).

Nas Figuras 1, 2 e 3, estão apresentadas as curvas de variação do torque em função do tempo dos polímeros puros, das blendas com e sem compatibilizante. A Figura 1 ilustra as curvas de torque para os polímeros puros. Observa-se que, após $3 \mathrm{~min}$. de processo, o torque tende a ficar praticamente constante, com pequenas oscilações em torno de um valor médio. Esse comportamento indica estabilidade da viscosidade para as condições de processo utilizadas, ou seja, velocidade de $60 \mathrm{rpm}$ e temperatura de $240^{\circ} \mathrm{C}$. O polietileno de alta densidade enxertado com anidrido maleico (PE-g-MA) apresentou o maior torque quando comparado aos outros polímeros e, portanto, maior viscosidade nessas condições. 


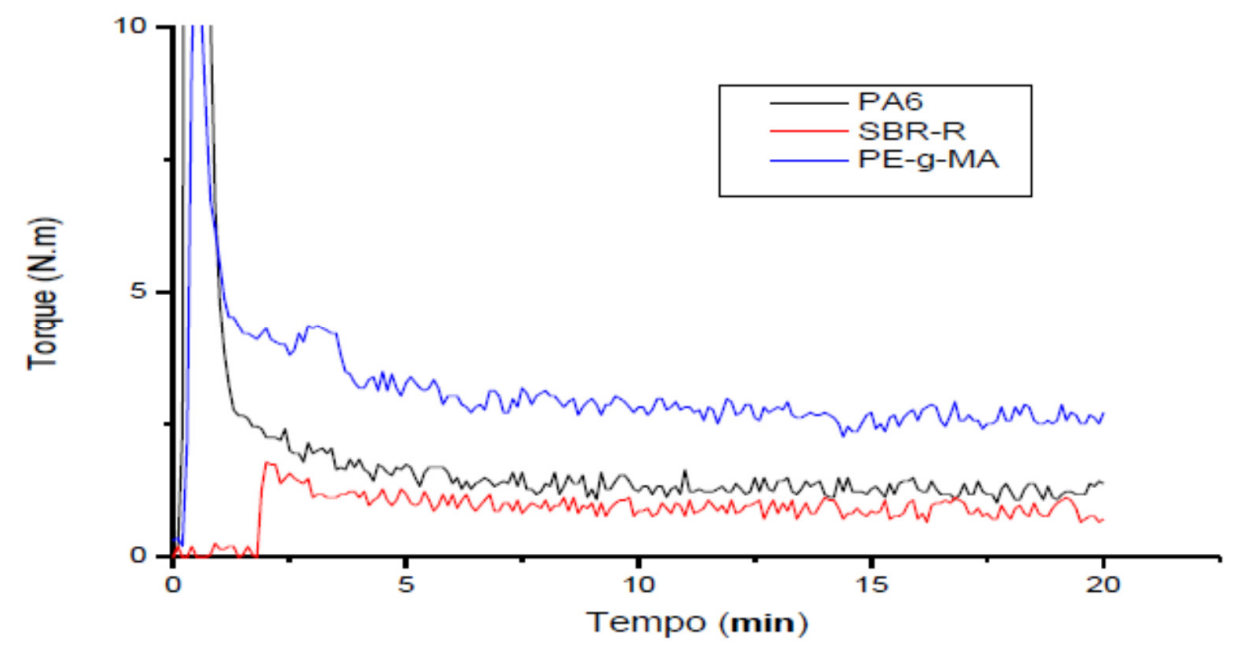

Figura 1 - Curvas de torque em função do tempo dos polímeros puros.

A Figura 2 ilustra as curvas de reometria de torque para as blendas binárias PA6/SBR$\mathrm{R}$ 90/10, 80/20, 70/30 e 60/40 (\% em peso). Observa-se que os valores de torque das blendas aumentam com o aumento da percentagem do SBR-R adicionado, implicando na elevação da viscosidade, provavelmente porque o SBR-R esteja agindo como uma carga.

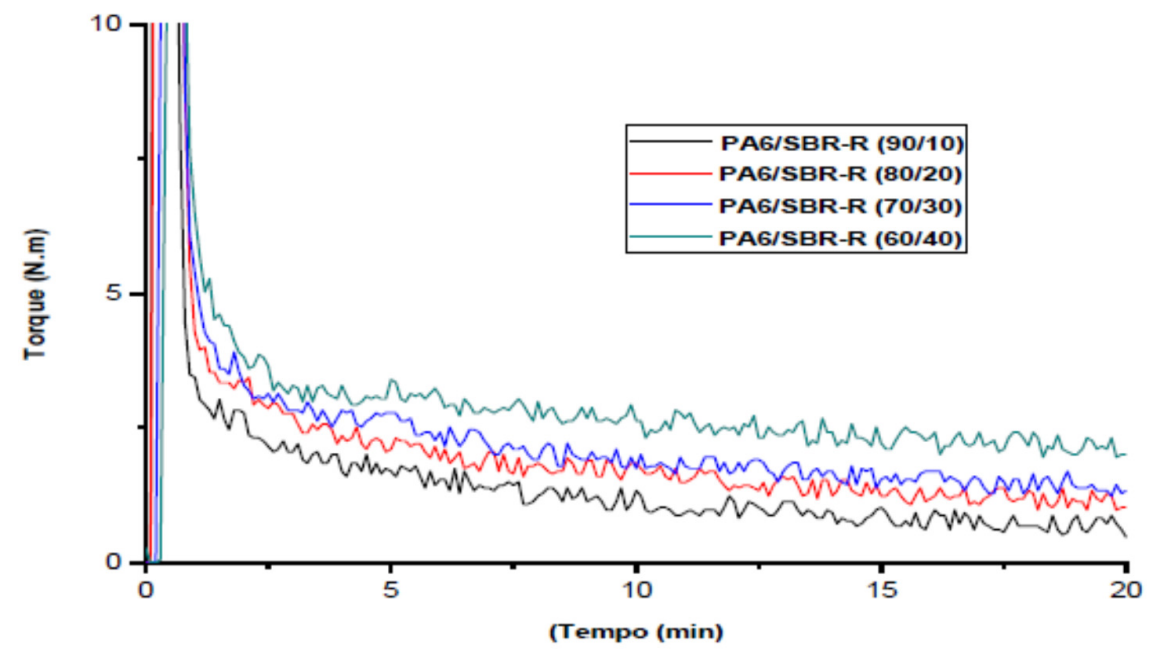

Figura 2 - Curvas de torque em função do tempo das blendas binárias.

A Figura 3 ilustra as curvas de reometria de torque das blendas ternárias PA6/SBRR/PE-g-MA, variando-se o teor do SBR-R e mantendo-se constante, em 5\% (em peso) o teor do compatibilizante PE-g-MA. Observa-se que os valores dos torques das blendas PA6/SBRR/PE-g-MA $(67,5 / 27,5 / 5)$ e $(57,5 / 37,5 / 5)$ com maiores percentagens de SBR-R foram maiores se comparados com as outras blendas, o que mostra que o torque aumenta com o aumento da percentagem de SBR-R adicionado à mistura, implicando na elevação de viscosidade. Nota-se nestas blendas, que o torque não aumentou com a presença do PE-g-MA, indicando que não houve reações. 


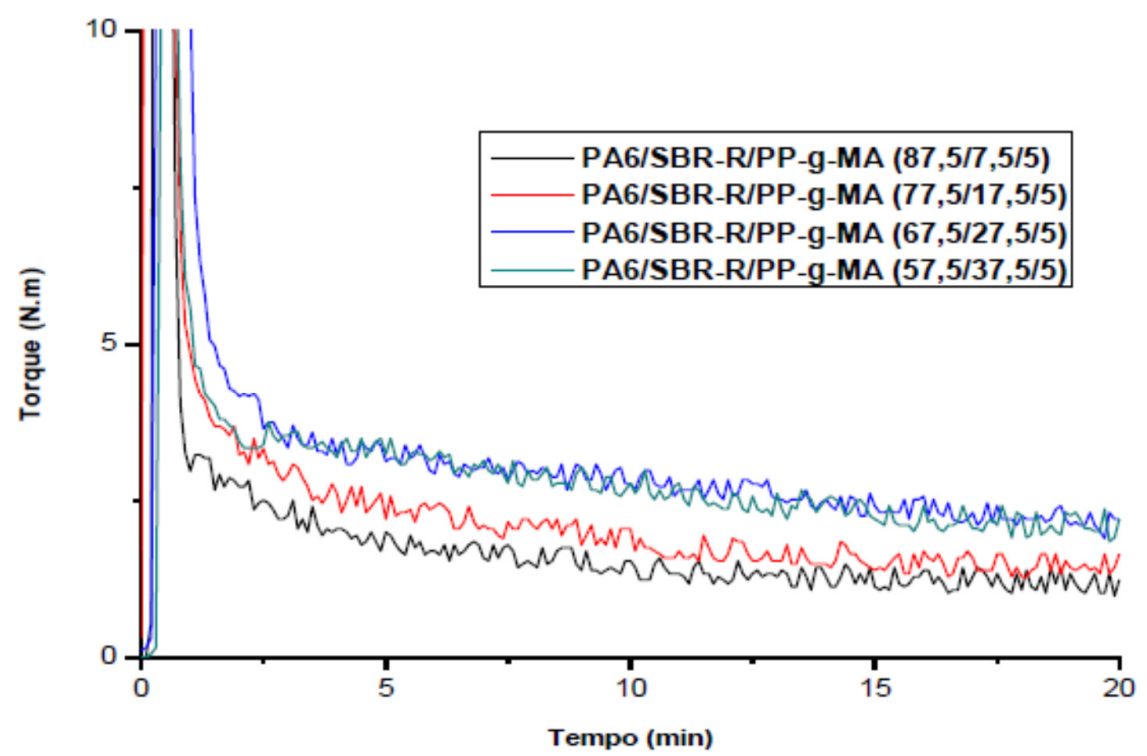

Figura 3 - Curvas de torque em função do tempo das blendas ternárias.

Observa-se nas Figuras 2 e 3 que, no geral, tanto as blendas binárias quanto as ternárias aumentam a viscosidade, à medida que aumenta o teor de borracha. Esse aumento na viscosidade será maior em função do resíduo de SBR-R ser um polímero já reticulado que resistirá a fluir durante o processo (SERRANO, 2009). De acordo com a literatura, esses resultados das blendas binária e ternárias, com o aumento de SBR-R, podem ser consequência da ocorrência de processos de entrecruzamentos de cadeias, devido à insaturação presente na cadeia do elastômero (LIBIO, 2011).

Temperatura de deflexão térmica

A Figura 4 apresenta as temperaturas de deflexão térmica da PA6 e das blendas binárias e ternárias. Verifica-se que o valor máximo da HDT foi de $110^{\circ} \mathrm{C}$ para a PA6 e o menor valor de $99^{\circ} \mathrm{C}$ para a blenda ternária PA6/SBR-R/PE-g-MA 77,5/17,5/5 (\% em peso). Observa-se que a HDT das blendas compatibilizadas e sem compatibilizante reduziram pouco em comparação a PA6. Os valores observados nessas blendas são muito interessantes do ponto de vista tecnológico para aplicações industriais, uma vez que são valores próximos ao da PA6 pura, ou seja, não houve uma grande perda da HDT. 


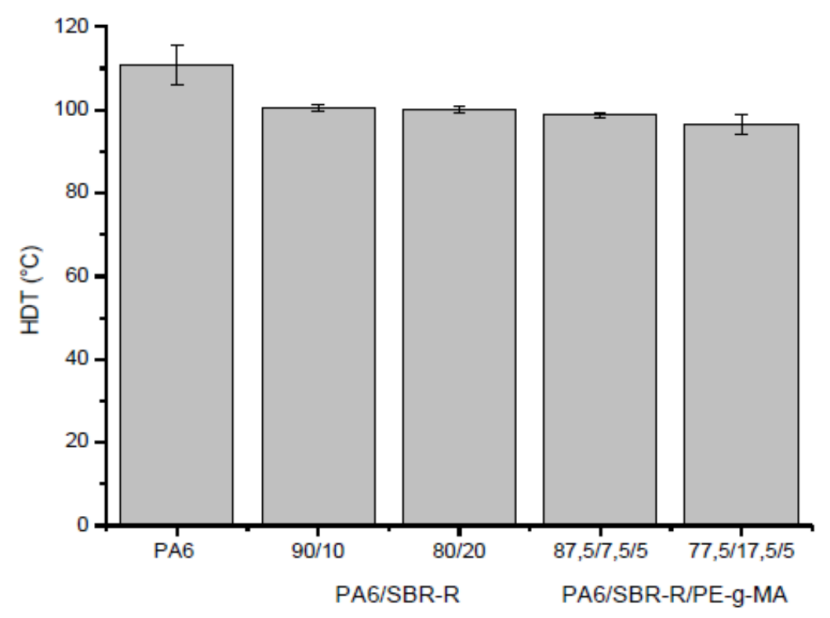

Figura 4 - Temperatura de deflexão térmica da PA6, das blendas binárias e ternárias.

A temperatura de deflexão térmica não sofre influência com a variação da maioria das variáveis, mas somente com o aumento do teor de borracha (GRASSI; FORTE, 2001). Observa-se, na Figura 4, que, à medida que aumenta o teor de borracha nas blendas binárias e ternárias, decai a HDT de forma moderada, ou seja, uma queda quase desprezível. No geral, nota-se que, das blendas processadas, a binária na proporção 90/10\% obteve o resultado mais expressivo. As características mais importantes no desempenho de uma blenda sob temperatura de deflexão térmica são a contribuição individual dos componentes e a morfologia gerada pelas fases nas blendas. Geralmente, a fase contínua numa morfologia de fases proporciona maior contribuição a HDT da blenda polimérica. A fase contínua, na maioria das vezes, é a própria matriz da blenda (FERREIRA; PESSAN; HAJE JÚNIOR, 1997). Então, provavelmente a PA6 como a matriz das blendas processadas contribuiu mais significativamente na temperatura de deflexão térmica do que o SBR-R nesta blenda 90/10\%.

Análise térmica dinâmico-mecânica (DMTA)

Ensaios dinâmico-mecânico utilizam métodos que compreendem a variação da temperatura e/ou da frequência, medindo-se a quantidade de energia armazenada (módulo de armazenamento) e a quantidade de energia dissipada (módulo de perda), na forma de calor pelo material. A razão entre os módulos de armazenamento e perda, denominada tangente de delta (tanঠ), permite avaliar a diferença entre o componente elástico e viscoso do material. O módulo de armazenamento corresponde à resposta elástica, sendo que quanto mais rígido for o material, maior será seu módulo de armazenamento. O módulo de perda corresponde à resposta viscosa, de maneira que, quanto mais flexível, maior o módulo de perda do material, e maior sua capacidade de dissipar energia mecânica (FIEGENBAUM, 2007).

Por meio da análise térmica dinâmico-mecânica (DMTA), podem-se estimar mudanças de relaxações moleculares que ocorrem em materiais poliméricos em uma ampla faixa de temperatura. $\mathrm{O}$ conhecimento dessas mudanças permite relacionar parâmetros moleculares e propriedades mecânicas de polímeros. 
Na Figura 5 (a) e 5 (b), são mostrados os valores de tanঠ e do módulo de armazenamento (E'), da PA6 e das blendas binárias e ternárias, com $5 \%$ em peso de PE-g$\mathrm{MA}$, em função da temperatura, respectivamente. Observa-se que a PA6 apresenta dois picos em, aproximadamente, $-7^{\circ} \mathrm{C}$ e $61^{\circ} \mathrm{C}$. A primeira transição pode estar relacionada à relaxação $\beta$ e a outra seria a própria $\mathrm{Tg}$, atribuída à relaxação $\alpha$. Para as blendas binárias e ternárias, houve o deslocamento dos picos para, aproximadamente, $-10^{\circ} \mathrm{C}$ e o deslocamento da relaxação a da PA6 para valores maiores.

Na Figura 5 (b), observa-se que a altura do patamar do pico de módulo de armazenamento, observado depois do pico da $\mathrm{Tg}$ da PA6, que apareceu a $25^{\circ} \mathrm{C}$, pode ser relacionada ao módulo elástico da blenda, ou seja, quanto mais alto, maior é a energia armazenada e maior o módulo elástico do material. Logo, à medida que a quantidade de borracha foi aumentada, maior a altura desse patamar e intensidade dos picos e maior o módulo elástico.

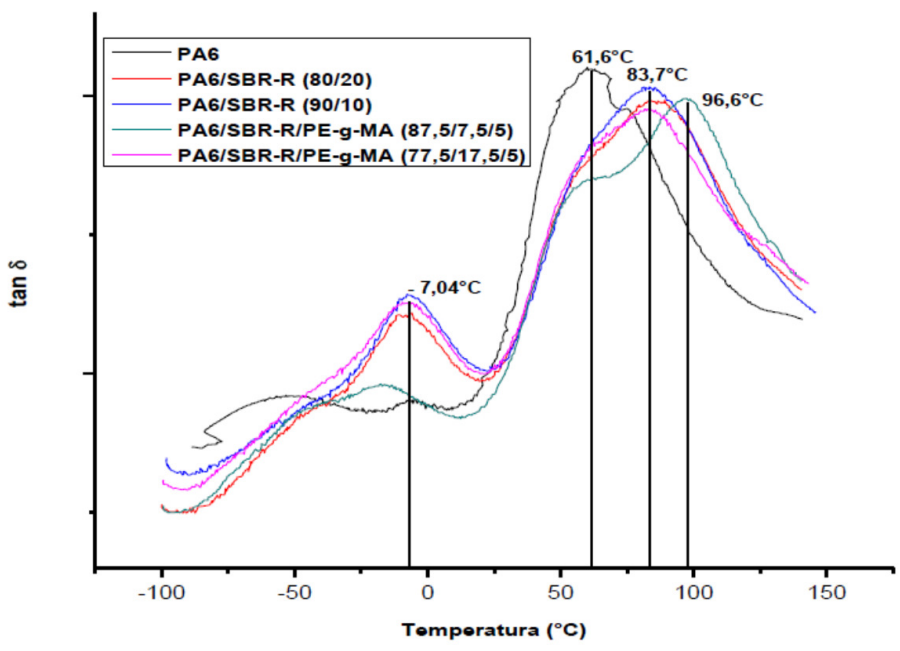

(a)

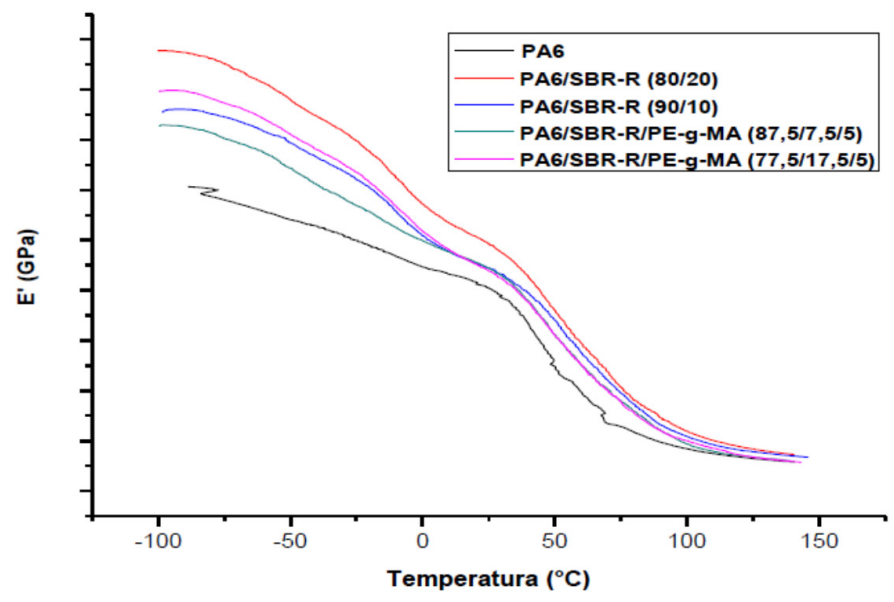

(b)

Figura 5 - Curvas de tanס (a) e do E' (b) em função da temperatura para a PA6 e as blendas binárias (PA6/SBR-R) e ternárias (PA6/SBR-R/PE-g-MA). 
Espectroscopia na região do infravermelho com transformada de Fourier (FTIR)

A espectroscopia no infravermelho é, certamente, uma das mais importantes técnicas analíticas disponíveis atualmente. Uma das grandes vantagens dessa técnica é que grande parte das amostras, em praticamente qualquer estado físico, pode ser estudada. A introdução de espectrômetro de infravermelho com transformada de Fourier (FTIR) melhorou, drasticamente, a qualidade dos espectros no infravermelho e minimizou o tempo necessário para obtenção de dados. A radiação infravermelha corresponde, aproximadamente, à parte do espectro eletromagnético situada entre as regiões do visível e micro-ondas. A porção de maior utilidade na análise e identificação de materiais está situada entre $4000 \mathrm{~cm}^{-1}$ até 400 $\mathrm{cm}^{-1}$ (2,5 $\mu \mathrm{m}$ e $25 \mu \mathrm{m}$ ), o chamado infravermelho médio (HAACK, 2010).

A técnica de espectroscopia foi utilizada para caracterização dos componentes puros e das blendas binárias e ternárias, com $5 \%$ em peso de PE-g-MA.

Na Figura 6, estão ilustrados os espectros de FTIR da PA6, SBR-R e o PE-g-MA puros. Observam-se bandas características da PA6 e que são representadas por $(\mathrm{CH} 2)_{5}$, aproximadamente, em $1300 \mathrm{~cm}^{-1}, \mathrm{~N}-\mathrm{H}$ e C=O entre $1500-1750 \mathrm{~cm}^{-1}$ e estiramento do grupo $\mathrm{N}-\mathrm{H}$ aproximadamente, em $3300 \mathrm{~cm}^{-1}$, e a presença de picos característicos do SBR, como o $\mathrm{C}-\mathrm{H}$ (substituição aromática) entre $3000 \mathrm{~cm}^{-1}$ e $4000 \mathrm{~cm}^{-1}$, conforme também reportado por Silva (2011).

Nas Figuras 7 e 8, estão ilustrados os espectros de FTIR das blendas binárias PA6/SBR$R$, contendo 10 e $20 \%$ em peso de SBR-R e das blendas ternárias PA6/SBR-R/PE-g-MA, contendo $5 \%$ em peso de compatibilizante PE-g-MA. Observa-se que as bandas características da PA6 não foram modificadas pela presença do SBR-R e nem pelo aumento da sua percentagem nas blendas binárias e pela presença de PE-g-MA nas blendas ternárias, mostrando que os seus grupamentos químicos não foram afetados.

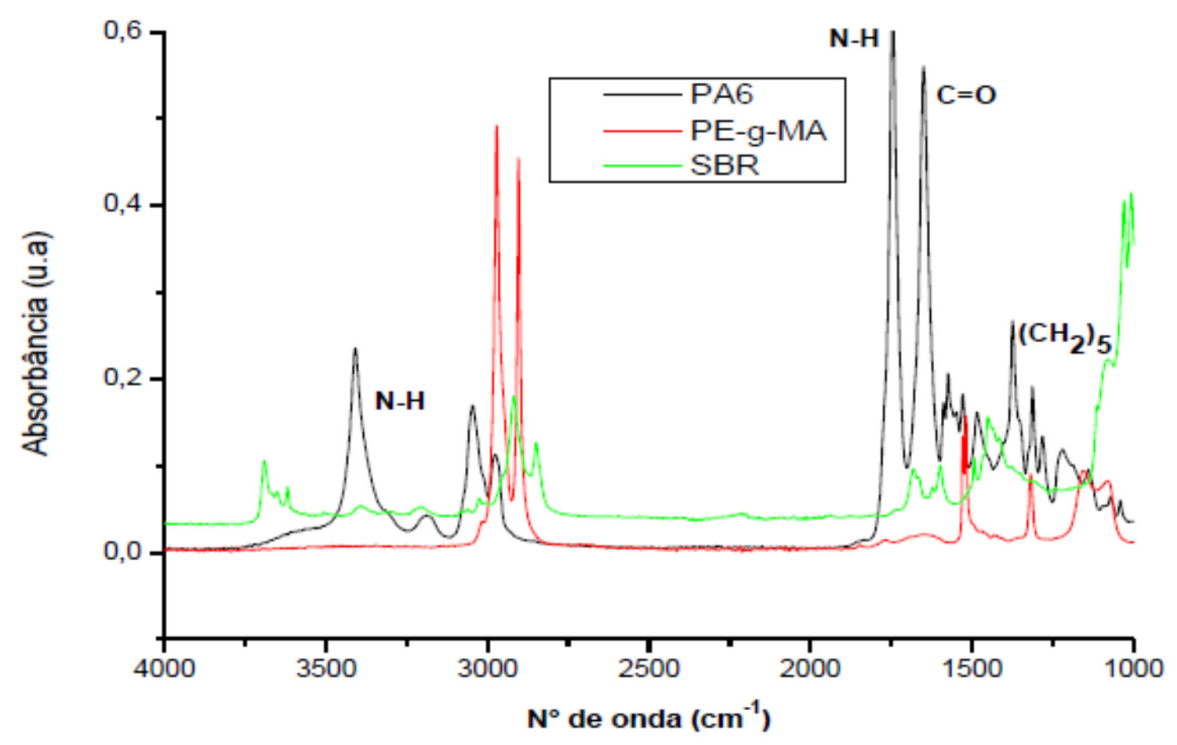

Figura 6 - Espectros de FTIR da PA6, SBR-R e PE-g-MA puros. 


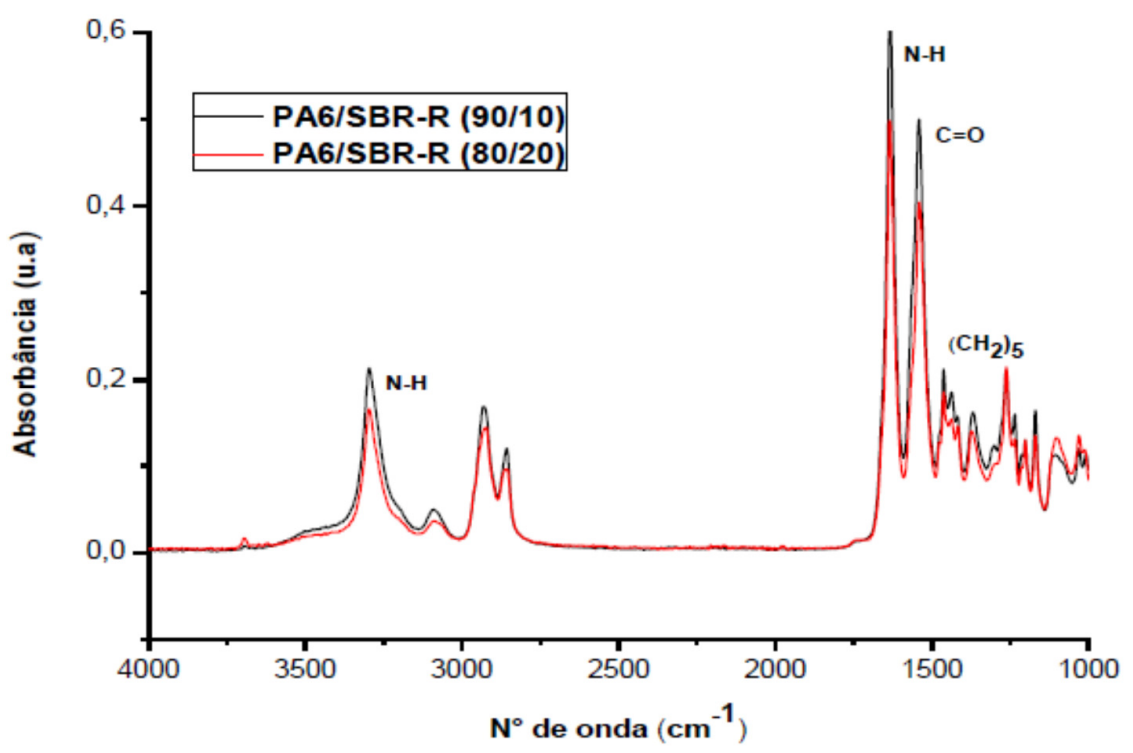

Figura 7 - Espectros de FTIR das blendas binárias (PA6/SBR-R).

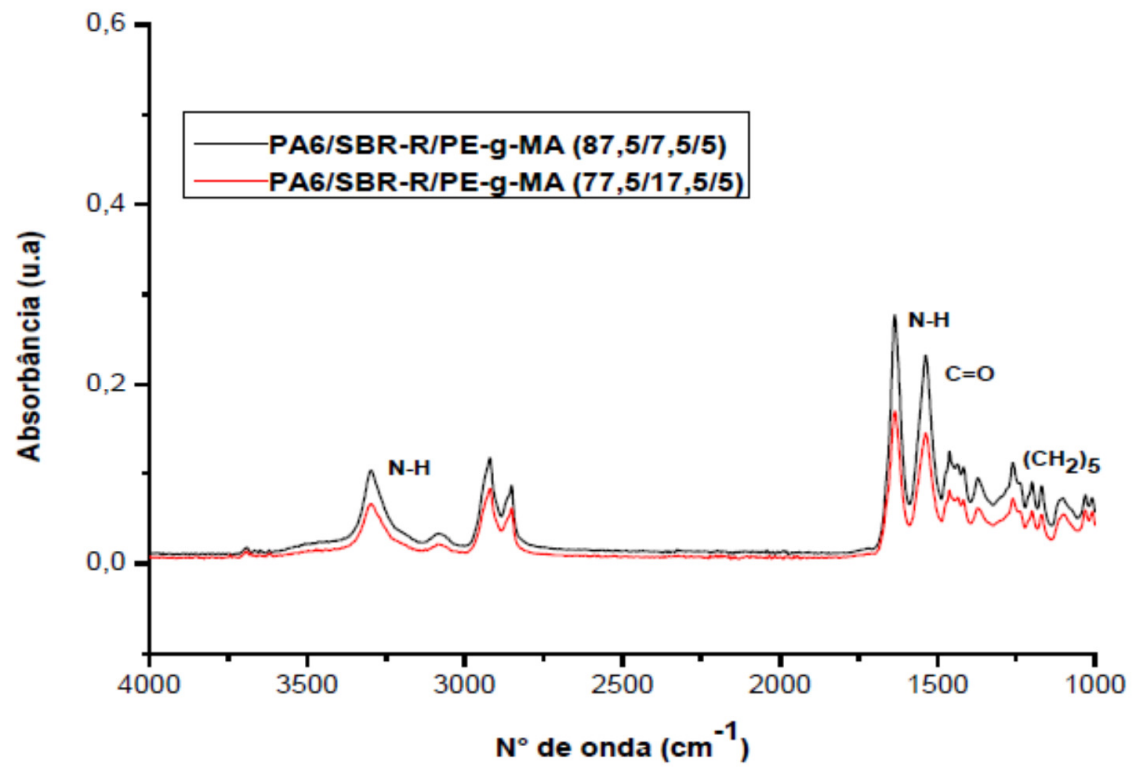

Figura 8 - Espectros de FTIR das blendas ternárias (PA6/SBR-R/PE-g-MA).

\section{CONCLUSÃO}

Blendas de PS/composto de borracha reciclada foram produzidas e podem ser adequadas, do ponto de vista tecnológico, para aplicações industriais, apesar de não apresentar diferenças significativas nas propriedades estudadas são uma boa alternativa para reciclagem dos compostos de SBR-R, resultando num novo material com propriedades específicas. Além disso, o reaproveitamento desses resíduos industriais pode reduzir os efeitos nocivos sobre o meio ambiente, bem como agregar valor a um material que seria descartado. 


\section{AGRADECIMENTOS}

Os autores agradecem à CAPES (Coordenação de Aperfeiçoamento de Pessoal de Nível Superior), pela concessão de bolsa de estudo do mestrado e a São Paulo Alpargatas/PB, pelo fornecimento das matérias primas.

\section{REFERÊNCIAS}

ARAÚJO, E. M.; CARVALHO, L. H.; MARCUS, V. L. F. Propriedades mecânicas de blendas PS/resíduos de borracha-influência da concentração, granulometria e método da moldagem. Polímeros: Ciência e Tecnologia, v. 19, n. 3, pp. 45-52, 1997.

ARAÚJO, E. M. Tenacificação da poliamida $6 \mathrm{com}$ abs por meio da técnica de compatibilização in situ com o uso de copolímeros acrílicos reativos. 2001. Tese (Doutorado em Ciência e Engenharia de Materiais) - Universidade Federal de São Carlos, São Carlos, SP, 2001.

AGRAWAL, P.; ARAÚJO, E. M.; MÉLO, T. J. A. Reometria de torque, propriedades mecânicas e morfologia de blendas compatibilizadas de PA6/PEAD. Polímeros: Ciência e Tecnologia, v. 18 , n. 2, pp. 152-157, 2008.

BARRA, G. M. O. et al. Blendas de poliamida 6/elastômero: propriedades e influência da adição de agente compatibilizante. Polímeros: Ciência e Tecnologia, v. 13, n. 2, pp. 94-101, 2003.

CARONE JÚNIOR, E. Propriedades mecânicas e térmicas, morfologia e reologia de blendas de poliamida-6 e elastômero. 1999. Tese (Doutorado em Química) - Universidade Estadual de Campinas, Campinas, São Paulo, 1999.

FERREIRA, L. A. S.; PESSAN, L. A.; HAJE JÚNIOR, E. comportamento mecânico e termomecânico de blendas poliméricas PBT/ABS. Polímeros: Ciência e Tecnologia, v. 19, n. 3, pp. 67-72, 1997.

FIEGENBAUM, F. Estudo da compatibilização das blendas PP/PA6 e PA6/EPR. 2007. Dissertação (Mestrado em Ciência e Engenheira de Materiais) - Universidade Federal do Rio Grande do Sul, Porto Alegre, 2007.

GRASSI, V. G.; FORTE, M. M. C. Aspectos morfológicos e relação estrutura-propriedades de poliestireno de alto impacto. Polímeros: Ciência e Tecnologia, v. 11, n. 3, pp. 158-168, 2001.

HAACK, M. S. Análise de materiais por espectroscopia no infravermelho dentro do sistema de gestão de qualidade conforme ABNT NBR ISSO/IEC 17025. 2010. Trabalho de Graduação (Graduação em Química) - Universidade Federal do Rio Grande do Sul, Porto Alegre, 2010.

LIBIO, I. C. Efeito de agentes de compatibilização em blendas de PS/EPDM. 2011. Dissertação (Mestrado em Ciência e Engenheira de Materiais) - Universidade Federal do Rio Grande do Sul, Porto Alegre, 2011. 
OLIVEIRA, A. D.; LAROCCA, N. M.; PESSAN, L. A. Efeito da sequência de mistura nas propriedades de blendas PA6/ABS compatibilizadas com o copolímero SMA. Polímeros: Ciência e Tecnologia, v. 21, n. 1, pp. 27-33, 2011.

SERRANO, C. L. R. Uso de resíduos de SBR proveniente da indústria de calçados em composição de SBR. 2009. Tese (Doutorado em Ciência dos Materiais) - Universidade Federal do Rio Grande do Sul, Porto Alegre, 2009.

SILVA, D. F. Desenvolvimento de blendas de poliamida 6/composto de borracha reciclada. 2011. Dissertação (Mestrado em Ciência e Engenharia dos Materiais) Universidade Federal de Campina Grande, Campina Grande, PB, 2011.

SILVA, D. F.; ARAÚJO, E. M.; MELO, T. J. A. Desenvolvimento de blendas de poliamida 6/composto de borracha reciclada (SBRr). Revista Eletrônica de Materiais e Processos, v. 7, n. 2, pp. 104-110, 2012.

SILVA, D. F. et al. Desenvolvimento de blendas de poliestireno/composto de borracha reciclada (SBRr). In: CONGRESSO BRASILEIRO DE POLÍMEROS (CBPol). 12, 2013, Florianópolis. Anais... Florianópolis, 2013. pp. 1-4. 